\title{
AUMENTO DA EFICIÊNCIA ENERGÉTICA COM A MODERNIZAÇÃO DE VENTILADORES DE PROCESSO*
}

Cláudio S. S. Pinto ${ }^{1}$

\section{Resumo}

Em face do agravamento da situação da energia elétrica no Brasil, com disponibilidade cada vez mais restrita e custo cada vez maior, torna-se urgente reduzir o seu consumo onde possível. Ventiladores centrífugos de processo de médio e grande porte são grandes consumidores de energia elétrica e podem ter um elevado potencial para a redução do seu consumo. Este texto mostra como identificar a possibilidade de economizar o uso da energia elétrica em um determinado ventilador e que modificações ele necessita para cumprir este objetivo.

Palavras-chave: Eficiência energética; Modernização; Retrofit; Ventilador de processo.

\section{INCREASE ENERGY EFFICIENCY WITH THE RETROFIT OF PROCESS FANS Abstract \\ In view of the deterioration of the electricity situation in Brazil, with increasingly restricted availability and increasing cost, it is urgent to reduce their consumption where possible. Medium and large centrifugal fans are large consumers of electricity and may have a high potential for reducing its consumption. This text shows how to identify the possibility to save the use of electricity in a given fan and what changes he needs to fulfill this goal.}

Keywords: Energetic efficiency; Modernization; Retrofit; Process fan. 


\section{INTRODUÇÃO}

Há décadas que praticamente todos os ventiladores de processo são dimensionados para operar com a maior eficiência possível, com base nos dados solicitados pelos projetistas.

Entretanto, muitos deles podem não estar operando com a elevada eficiência projetada por diversos motivos, entre os quais se destacam: o projetista superestimou a pressão (perda de carga) na especificação original, a colocação de filtro adicional no sistema, o aumento na capacidade de algum equipamento do sistema, a mudança no layout.

Para efetivamente economizar energia elétrica é necessário conhecer o ponto de operação atual do ventilador e, tendo ele potencial para reduzir o seu consumo de energia elétrica, substituir o rotor existente por outro com maior eficiência.

A experiência tem mostrado que é possível obter a redução do consumo de energia elétrica do ventilador com surpreendente pay-back.

\section{MATERIAIS E MÉTODOS}

O principal objetivo deste texto é mostrar como é possível economizar energia elétrica de forma substancial em ventiladores centrífugos de processo.

Evidentemente, que estes princípios se aplicam a todos os ventiladores de processo, porém são mais justificáveis em ventiladores de médio e grande porte, onde a economia pode ser da ordem de dezenas ou centenas de quilowatts por hora, ou centenas ou milhares de megawatts por ano.

\subsection{Auditoria Energética}

Para conhecer a eficiência energética atual do ventilador é necessário medir o seu ponto de operação através da realização de uma auditoria energética, ou seja, medir os seus parâmetros de operação, a saber, vazão, pressão, temperatura e consumo de energia elétrica.

Os instrumentos utilizados na auditoria energética são basicamente: tubo de Prandtl (ou tubo de Pitot), manômetro digital para pressões estática e dinâmica, termômetro digital, tacômetro digital, amperímetro.

As medições da auditoria energética, apesar de aparentarem ser simples, necessitam ser feitas por técnicos experientes.

A auditoria energética para ser conclusiva necessita que o ventilador esteja operando com a plena capacidade de operação.

Com os valores medidos na auditoria energética calcula-se a sua eficiência energética e, se houver potencial de economia de energia, por exemplo, aumentar a sua eficiência em $10 \%, 20 \%$ ou mais, procura-se encontrar dentro da completa gama de rotores disponível na Reitz, aquele que se ajuste à carcaça do ventilador existente e que tenha a maior eficiência possível.

\subsection{Controle do Ventilador}

Usualmente o ventilador de processo é controlado por um registro com pás reguláveis colocado na sua entrada (registro radial ou registro de venezianas) ou através da variação da sua rotação por meio de inversor de frequência. 
Se o ventilador for controlado por uma válvula (ou damper) instalada no duto do sistema, significa que ele pode estar "jogando fora" muita energia, pois este tipo de controle apenas regula a perda de carga do processo. A simples substituição desta válvula do duto por um registro na entrada do ventilador, ou a instalação de um inversor de frequência, já pode reduzir significativamente o consumo de energia elétrica do ventilador.

A utilização do registro na entrada do ventilador, ou do inversor de frequência, em conjunto com o retrofit do ventilador (explicação a seguir) potencializa ainda mais a economia de energia.

\subsection{Retrofit}

Retrofit é a palavra atualmente utilizada para definir atualização/modernização e/ou aumento de capacidade de máquinas e equipamentos existentes através da substituição ou modificação de peças.

Retrofit de ventilador centrífugo significa a substituição do rotor existente por outro mais moderno e com elevada eficiência, tanto visando economia de energia elétrica (como é o tema desta apresentação) quanto o aumento da sua vida útil quando ele estiver submetido a elevado desgaste.

No retrofit do ventilador a Reitz procura aproveitar a maior quantidade possível das peças existentes, normalmente restringindo-se somente a troca do conjunto rotor + eixo e do(s) cone(s) aspirante(s) da carcaça.

Além disso, a Reitz somente faz alguma intervenção na carcaça do ventilador existente se for inevitável.

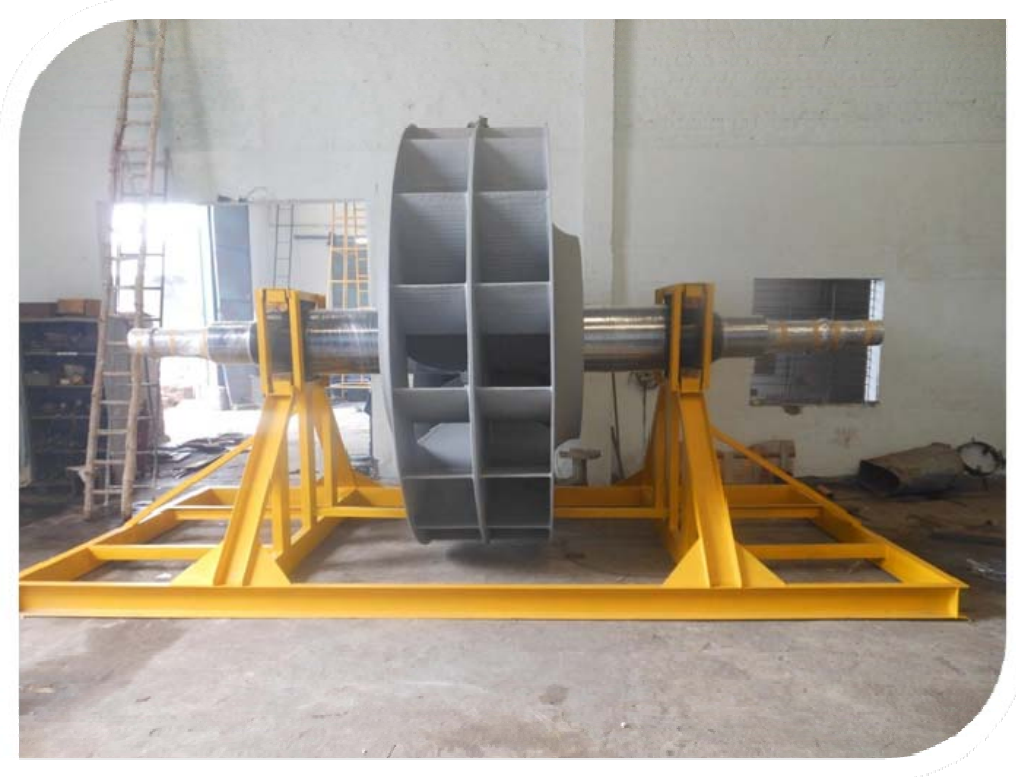

Figura 1: Conjunto Rotor + Eixo de Ventilador Centrífugo de Dupla Aspiração

\section{RESULTADOS E DISCUSSÃO}

A seguir os resultados de um caso real. 


\subsection{Objetivo}

Melhorar a eficiência energética de um ventilador centrifugo utilizado no processo de exaustão de gases do forno numa fábrica de cimento.

\subsection{Medição do Ponto de Operação do Ventilador Existente}

Através da realização de uma auditoria energética no ventilador foram medidos os seguintes parâmetros:

- Vazão:

- Pressão Estática:

- Rotação:

- Consumo de Energia:

- Eficiência (calculada):

$\begin{array}{rl}414.000 & \mathrm{~m}^{3} / \mathrm{h} \\ 900 & \mathrm{~mm} \mathrm{CA} \\ 950 & \mathrm{rpm} \\ 1.462 & \mathrm{~kW} \\ 69,4 & \%\end{array}$

\subsection{Solução Adotada}

Com base nos dados medidos na auditoria energética foi executado um retrofit no ventilador existente com a substituição apenas das seguintes peças:

- Rotor

- Eixo

- Cone de Entrada da Carcaça

\subsection{Parâmetros de Operação do Ventilador Modernizado}

Após a execução do retrofit os parâmetros medidos foram:

- Vazão:

$414.000 \mathrm{~m}^{3} / \mathrm{h}$

- Pressão Estática:

$900 \mathrm{~mm} \mathrm{CA}$

- Rotação:

- Consumo de Energia:

$950 \mathrm{rpm}$

- Eficiência (calculada):

$77,4 \%$

\subsection{Resultado}

A modernização do ventilador resultou num aumento de 8 pontos porcentuais na eficiência do ventilador, ou seja, economia de 10\% (150 kW) no consumo de energia elétrica.

Neste caso em particular, o pay-back do retrofit executado no ventilador foi de aproximadamente 8 meses.

\section{CONCLUSÃO}

Em última análise, a realização de retrofit em ventilador de processo, quando aplicável, proporciona:

- Diminuir custos (economia de energia elétrica, aumento da vida útil do rotor).

- Aumentar a produtividade da fábrica.

- Aumentar a confiabilidade no equipamento.

- Trocar peças internas obsoletas.

- Ajudar o meio ambiente. 